\title{
Title: Development and pilot testing of a Measure of potential barriers and facilitators to the Use of a Standardized assessment Tool (MUST)
}

Priscilla Lam Wai Shun, OT, MSc: Doctoral Candidate, Occupational Therapy Program, School of Rehabilitation, Université de Montréal, Montreal, Quebec, Canada.

Carolina Bottari, OT, PhD: Associate Professor, Occupational Therapy Program, School of Rehabilitation, Université de Montréal, Montreal, Quebec, Canada and Researcher, Centre for Interdisciplinary Research in Rehabilitation of Greater Montreal

This is an Accepted Manuscript version of the following article, accepted for publication in the Journal of Continuing Education in Health Professions: Lam Wai Shun, P., \& Bottari, C. (2018). Development and Pilot Testing of a Measure of Potential Barriers and Facilitators to the Use of a Standardized Assessment Tool. J Contin Educ Health Prof, 38(2), 94-101. https://doi.org/10.1097/CEH.0000000000000194. It is deposited under the terms of the Creative Commons Attribution-NonCommercial License (http://creativecommons.org/licenses/by-nc/4.0/), which permits non-commercial re-use, distribution, and reproduction in any medium, provided the original work is properly cited.

\section{Corresponding author:}

Dr. Carolina Bottari

Faculty of Medicine, School of Rehabilitation, Université de Montréal

C.P. 6128 Succursale Centre-Ville

Montreal (Québec)

Canada, H3C $3 J 7$

Telephone number: 514-343-6111, ext. 44048

Email: carolina.bottari@umontreal.ca

\section{Conflicts of Interest and Source of Funding}

The authors declare no conflict of interest. This study was carried out with the financial support of the Fonds de recherche du Québec - Santé (FRQS), grant number 33403. 


\title{
Development and pilot testing of a Measure of potential barriers and facilitators to the Use of a Standardized assessment Tool
}

\begin{abstract}
Introduction: Standardized assessment tools (SATs) are essential to evidence-based assessment practices. Identifying what impedes clinicians' use of a SAT can help tailor strategies promoting its use in clinical practice. This article presents the development of the Measure of potential barriers and facilitators to Using a Standardized assessment Tool (MUST) questionnaire. Preliminary findings are also reported from pilot testing in which the MUST was used to investigate occupational therapists' (OTs) perceptions of potential barriers and facilitators to the use of the Activities of Daily Living Profile (ADL Profile), a SAT evaluating independence in everyday activities of cognitively impaired adults.

Methods: The MUST was administered to 41 OTs attending continuing education workshops on the ADL Profile. Internal consistency was explored using Chronbach's alpha. Descriptive statistics were used to analyse scores for each statement.

Results: Internal consistency for subscales related to clinicians' characteristics $(\alpha=0.7)$ and to the SAT's characteristics $(\alpha=0.8)$ were adequate but lower for the subscale related to the clinical setting $(\alpha=0.6)$. OTs' perceptions of potential barriers were associated with: OTs' perceived selfefficacy; ADL Profile's applicability to their clienteles, compatibility with values promoted in their work setting and with their clients' preferences; limited peer support and time to implement the ADL Profile.
\end{abstract}


Discussion: The MUST, a theory-informed questionnaire, may prove useful in identifying potential barriers needing to be adressed in continuing education training promoting the use of SATs by clinicians. The MUST is quick to administer and initial testing provides support for its internal consistency.

Keywords: standardized assessment tool, evidence-based assessment, questionnaire development, research/education, knowledge translation, implementation 
Evidence-based practice is recognized as essential to clinical decisions leading to improved patient outcomes ${ }^{1-3}$. Although evidence-based practice targets both effective treatment and assessment practices, more emphasis has been placed on interventions and less attention has been paid to evidence-based assessment (EBA) practices ${ }^{4}$. Clinicians engaging in evidence-based assessments are encouraged to use standardized assessment tools (SATs). SATs are essential in identifying health-related problems, guiding the choice of interventions and monitoring evolution ${ }^{5,6}$. However, routine use of SATs is known to be challenging for clinicians in certain practice contexts 7,8. In some areas of rehabilitation practice for example, a high percentage of clinicians report routinely using SATs ${ }^{9-11}$ while in other areas, the uptake remains low ${ }^{11-14}$. When rehabilitation clinicians do not use SATs with established reliability and validity, they run the risk of providing less than optimal rehabilitation interventions.

Although clinicians' attitudes toward SATs in general have been investigated ${ }^{15}$ and common barriers identified ${ }^{16}$, researchers working in collaboration with clinicians to implement a specific SAT in a targeted practice area need to identify local barriers and facilitators ${ }^{17}$. In this process, investigating clinicians' perceptions is indispensable as they are likely the key users of the SAT to be implemented. Knowing their perspectives can help develop and further tailor continuing education workshops or other strategies supporting effective implementation of a SAT in clinicians' practice ${ }^{17}$. Clinicians' perceptions of barriers to the use of various forms of scientific evidence has been extensively examined using qualitative approaches (using focus groups or interviews) or measured using quantitative approaches (using questionnaires) ${ }^{18,19}$. However, questionnaires have often been developed haphazardly without benefitting from the contribution of solid conceptual frameworks developed to guide implementation efforts ${ }^{19}$. And, to the best of 
our knowledge, there is presently no questionnaire aimed specifically at measuring clinicians' perceptions of barriers to the implementation of a SAT in their clinical practice.

The purpose of this article is to present the development and initial testing of the Measure of potential barriers and facilitators to the Use of a Standardized assessment Tool (MUST) questionnaire. This article also describes preliminary findings obtained from a pilot testing in which the MUST was used to investigate occupational therapists' (OTs) perceptions of potential barriers and facilitators to the clinical use of a SAT, the Activities of Daily Living Profile (ADL Profile) ${ }^{20,21}$.

\section{Initial development of the MUST questionnaire}

\section{Literature review}

A literature review was performed to identify conceptual frameworks that could help define constructs addressing clinicians' perceptions of barriers and facilitators to the use of a SAT. To the best of our knowledge, no conceptual framework specifically addresses potential barriers to the use of a SAT in clinical practice. The search was therefore broadened to conceptual frameworks describing barriers to clinicians' adherence to evidence-based practices. First, Domschroder et al.'s (2009) Consolidated Framework for Implementation Research (CFIR) was selected as an overarching framework providing an overview of factors that affect successful implementation of health innovations (e.g. interventions or assessments). The CFIR is based on a review of 19 implementation theories and frameworks and suggests that barriers at multiple levels can influence the use of health innovations. These include barriers associated with characteristics of the clinicians who are expected to use the innovation, characteristics of the innovation itself, and 
characteristics of the clinical context where the innovation is to be implemented ${ }^{19,22}$. Clinicians' behaviors and actions influence the success of implementation. Clinicians' characteristics known to facilitate or hinder the use of innovation include constructs such as knowledge, perceived selfefficacy, motivation and emotion. Key characteristics of an innovation also influence implementation and include constructs such as scientific evidence supporting the innovation, perception of the relative advantage of the innovation compared to other practices and costs associated with the innovation. Characteristics of the clinical setting that may influence clinicians use of innovations include environmental resources, organizational climate and time pressure.

Next, the literature search focused on finding determinant frameworks specifically aimed at understanding clinicians' perceptions of barriers. Determinant frameworks describe factors that have been found to influence implementation outcomes ${ }^{23}$. Two widely recognized conceptual frameworks were identified: the Theoretical Domains Framework (TDF) and the Clinical Practice Guideline Framework (CPGF). Numerous studies have examined their theoretical basis and used these frameworks to guide qualitative as well as quantitative approaches to evaluating barriers to implementation of scientific evidence ${ }^{24-29}$. The TDF is based upon several psychological theories describing factors that may hinder or enable changes in practice behaviors ${ }^{28,30}$. According to the TDF, factors influencing clinicians' behaviors can be categorized into eleven domains including knowledge, professional role and identity and environmental context. The CPGF was developed based on a literature review of barriers to physicians' adherence to clinical practice guidelines. It introduces constructs related to the clinician's knowledge, attitude and behavior and has been subsequently enriched to provide a comprehensive taxonomy of barriers and facilitators that can impact evidence-based decisions ${ }^{24}$. 


\section{Constructing the MUST questionaire}

Firstly, the two authors of this article (PL and CB), as well as a research assistant, compared constructs from the TDF and CPGF frameworks, merged constructs operationalizing the same concept and eliminated constructs irrelevant to the use of a SAT. This process yielded 22 constructs. Secondly, statements related to each construct were elaborated by PL and CB with special attention to avoiding repetitive statements, double negatives and ambiguous statements. The pilot version of the MUST comprised a total of 55 statements. Twelve statements were reverse worded to avoid response bias. 50 statements are generic, i.e. applicable to the investigation of barriers to the use of any given SAT (e.g. "I am familiar with the content of the tool). Five statements were written to specifically address particular characteristics of the SAT (i.e. the Activities of Daily Living Profile) that would be the object of interest in the following pilot study. Thirdly, constructs and associated statements were grouped into three broad categories of barriers described in the CFIR: barriers associated with clinicians' characteristics, with characteristics of the SAT itself and with the clinical setting (see description of these categories in the previous section). These categories constitute the three theoretical subscales of the MUST questionnaire. Finally, the chosen scoring format was a typical 5-point Likert scale: $1=$ Strongly disagree, $2=$ Disagree, 3= without opinion, 4= Agree, 5= Strongly agree. This scale is used to score each statement of the MUST questionnaire. It is worth noting that statements were not written as barriers or facilitators in themselves, it is the score given by participants on the likert scale that reflects clinicians' perception of potential barriers or facilitators. When statements are positively worded, scores of 1 and 2 are thought to reflect a potential barrier, scores of 4 and 5 thought to reflect a potential facilitator. When the statements are reverse worded, scores of 1 and 2 reflect a potential 
facilitator, scores 4 and 5 reflect a potential barrier. The content of the questionnaire was further examined by a third researcher not involved in the questionnaire development but with expertise in knowledge translation. This expert reviewed the constructs as well as statements included under each construct. Feedback led to the following modifications: two constructs were merged, a few statements were reworded for greater clarity and one statement was moved under another construct. Table 1 presents the three subscales with their associated constructs, construct definition and all statements included in the pilot version of the MUST.

$<$ Insert Table 1 about here >

\section{Methods}

Pilot testing of the MUST

Pilot testing of the MUST questionnaire was conducted to examine its internal consistency, to obtain feedback on clarity and pertinence of the MUST's statements and to collect preliminary data on OTs perceptions of potential barriers and facilitators to the use of a SAT, the Activity of Daily Living Profile (ADL Profile), in their clinical practice.

\section{Description of the SAT expected to be implemented: the ADL Profile}

The ADL Profile was developed to assess the level of independence of persons having sustained a traumatic brain injury when performing self-care activities (e.g. dressing), household activities (e.g. preparing a meal) and community activities (e.g. grocery shopping) ${ }^{20,31}$. The ADL Profile was developed with a special consideration for the impact of cognitive impairments, particularly executive dysfunctions, on a client's level of independence in activities carried out in the client's 
own real-world environment. For each activity, the clinician has to score the patient's level of independence $(0=$ dependent; $1 \mathrm{v}=$ verbal assistance required; $1 \mathrm{p}=$ physical assistance required, $2=$ independent with difficulty, $3=$ independent without difficulty) on each of the four following operations considered important components of executive functioning: formulating a goal, planning a task, executing a task and verifying the attainment of the initial goal. This procedure allows clinicians' to identify the executive dysfunction component that has the most impact on clients' ability to perform everyday tasks. The ADL Profile has been found valid and reliable when used with adults having sustained a traumatic brain injury ${ }^{21,32-34}$.

\section{Participant recruitment}

OTs attending continuing education workshops on the ADL Profile in <masked> (Canada), $<$ masked $>$ (Canada) and <masked $>$ (France) were invited to participate in the pilot testing of the MUST questionnaire. OTs who accepted to participate signed a consent form. Ethical approval was obtained from the Centre for Interdisciplinary Research in Rehabilitation of <masked>.

\section{Data collection}

Participating OTs completed the MUST questionnaire at the end of the workshops. Participating OTs from <masked> (Canada) were further asked to indicate statements that were redundant, unclear and not applicable to their work setting as well as the time required to complete the questionnaire. 


\section{Data analysis}

Item analysis was performed to explore the internal consistency of the MUST. Given that the statements and constructs were theoretically grouped in three subscales, Chronbach's alpha was calculated for each of the three subscales: clinician's characteristics, characteristics of the SAT, characteristics of the clinical setting. Descriptive statistics (median and range) were also used to analyse the scores given by OTs for each statement of the MUST. Scores for the twelve reverse worded statements were converted to allow for Chronbach's alpha calculations and to facilitate comparable calculations of the median and range.

\section{Results}

Participants characteristics

41 OTs participated in the pilot testing (years of clinical experience: mean $=9.9 ; \mathrm{SD}=6.7$ ). All OTs worked with adults with cognitive disturbances (27\% neurology or neurotraumatology, $29 \%$ geriatrics, $44 \%$ other) in various clinical settings (51\% acute care, $27 \%$ inpatient/outpatient rehabilitation, and $22 \%$ community settings). Participating OTs from <masked> (Canada) completed the questionnaire in an average of 12 minutes ( $\mathrm{SD}=4.7$ minutes).

\section{Internal consistency}

Chronbach's alphas ranging from 0.7 to 0.95 are usually considered acceptable ${ }^{35}$. Table 2 shows acceptable alphas for the subscales 'clinicians' characteristics' and 'characteristics of the SAT' but a slightly lower alpha for the subscale 'characteristics of the clinical setting'. Item-rest correlation for the last subscale reveals that statements $53(0.083)$ and $54(0.085)$ are poorly correlated with 
the rest of the subscale's items. Removal of statement 53 and 54 would increase Chronbach's alpha for this subscale to 0.805 . After reviewing the theoretical underpinnings of this subscale and the wording of the two statements, PL and CB decided to maintain statement 53 but reworded as follows: "I have the support that I need from my peers to implement the tool in my clinical practice". It was also agreed that the content of statement 54 was redundant and this statement was removed from the final version of the MUST questionnaire.

$<$ Insert Table 2 about here >

\section{Clarity and pertinence of statements}

Considering comments made by participants from <masked> (Canada), 13 statements were reworded, one statement eliminated and five added. The final version of the questionnaire includes 58 statements (48 generic to any measurement tool and 10 specific to the ADL Profile). See supplemental digital content for the final version of the MUST questionnaire.

Potential barriers and facilitators to the use of the ADL Profile by OTs

Table 3 presents the median and range of scores given by the entire group of participants for each statement of the MUST questionnaire. All OTs agreed or strongly agreed with the following four statements: 1, 4, 13, 17. As for potential barriers, the following six statements obtained the lowest median score of 2 (disagree): 16, 25, 35, 41, 49, 54 .

< Insert Table 3 about here > 


\section{Discussion}

The development of the MUST questionnaire was motivated by the need to design a theoryinformed questionnaire that could systematically and rapidly investigate the perception of a large group of clinicians regarding potential barriers and facilitators to the clinical use of a SAT. The MUST was easily administered, taking an average of 12 minutes to complete. Findings from pilot testing led to a few modifications to the MUST's statements and the final version of the MUST questionnaire includes 58 statements, of which 48 are generic to the use of any SAT.

This study also provided preliminary insights into OTs' perceptions of potential barriers and facilitators to the clinical uptake of the ADL Profile. All OTs agreed or strongly agreed with four statements, therefore suggesting that some elements may be potential facilitators to the use of the ADL Profile regardless of the practice context. All participating OTs perceived they had the knowledge to use the ADL Profile, they recognized the added value of the ADL Profile to their practice as well as the compatibility of the ADL Profile with their professional scope of practice. These results contrast with findings from other studies in which lack of knowledge and lack of perceived value regarding SAT use are commonly reported barriers ${ }^{16}$. In the MUST pilot testing, OTs completed the MUST questionnaire after participating in a continuing education workshop on the ADL Profile. Continuing education workshops have been shown to effectively address such barriers as lack of knowledge or lack of perceived value of the SAT to clinical practice ${ }^{36}$. Perception of potential barriers was more variable with six statements with a low median score, potentially reflecting remaining barriers to the use of the SAT. Since the MUST questionnaire was completed after the continuing education workshop on the ADL Profile, results suggest that the workshop could be further refined to address these remaining potential barriers. Regarding the 
perceived lack of compatibility between the tool and some clienteles or work settings, it must be highlighted that the ADL Profile was initially developed to assess the level of independence of persons having sustained a traumatic brain injury within their own home and community environment. Interest in using the tool with other populations or work settings has encouraged OTs to attend training on this tool but findings of this study suggest that further investigation on how to address the needs of various clienteles and work settings is warranted. Other persisting barriers pertained to lack of time and peer support. These findings are congruent with prior studies that have also shown these to limit the use of SATs in clinical practice ${ }^{16}$.

Findings from this study highlight that continuing education training is essential but insufficient in addressing all barriers to the implementation of a SAT. Considering the vast amounts of time and money that are invested in developing SATs and testing their psychometric properties as well as in training clinicians in their use, it is urgent that local obstacles to their use in clinical practice be identified so that implementation efforts can be adjusted accordingly ${ }^{37}$.

The MUST has proven useful to rapidly explore the perception of a large group of clinicians. Results obtained with the MUST provide initial insights on clinicians' perception of elements known to likely influence implementation. However, validating the results with a smaller group of OTs working in organizations where the SAT is to be implemented is necessary. Indeed, disagreeing with a statement in the MUST questionnaire does not automatically imply a barrier that the clinician would wish addressed to ensure his or her use of the SAT. Likewise, agreeing with a statement reflects a potential facilitator but does not automatically imply that it is a key element to successful use of the SAT by the clinician in his or her particular work setting. Although the results obtained with the MUST can provide direction, it is important to validate the results 
with follow-up questions in order to better interpret the results and better understand clinicians' needs in the implementation process. Lastly, the MUST was used with groups of OTs but given that it includes 48 generic statements, it has the potential to be used with any group of health care professionals who need to implement a SAT.

\section{Limitations}

Although the pilot testing allowed for exploration of the MUST's internal consistency, the convenience sample of participating OTs was too small to perform factor analysis. Some results of the item analysis may underestimate the reliability of the MUST questionnaire ${ }^{35}$. Also, the MUST questionnaire is based on determinant frameworks and is not intended to measure the process of translating evidence into practice. Although it can provide some insights into aspects of implementation interventions that need to be tailored to perceived barriers, it cannot be used in itself to guide the planning or execution of overall implementation efforts or to evaluate the process of implementation. Process models, such as the Knowledge-to-action model, are better suited for planning overall implementation phases and the MUST can be useful at the barriers assessment phase $^{17,23}$.

\section{Conclusion}

Continued education providers and researchers interested in promoting the use of a SAT by clinicians should be conscientious of developing continuing education training that address local barriers to the use of the SAT being promoted. The MUST is a theory-informed questionnaire that investigates clinicians' perceptions of potential barriers and facilitators to the use of a SAT. It may 
prove useful in tailoring the delivery of continuing education workshops as well as for research focusing on the implementation of SATs in clinical practice. The MUST is quick to administer and initial testing provides support for its utility and internal consistency. Further research is required to test its validity and reliability with various health care professionals using various SATs.

\section{Lessons for practice}

- The MUST, a theory informed questionnaire, provides a quick way to systematically investigate the perception of a large group of clinicians regarding potential barriers and facilitators to the use of a standardized assessment tool.

- Results obtain with the MUST questionnaire provide insights on potential barriers that may need to be addressed in continuing education training or in implementation strategies promoting the use of standardized assessment tools.

- Preliminary findings suggest that continuing education training helps to overcome some barriers to the use of a standardized assessment tool but is likely insufficient to ensure its uptake in routine clinical practice.

Acknowledgements: The authors would like to thank the occupational therapists who participated in this study. Many thanks to Georgia Iliopoulos (research assistant at the time of the study), Laurianne Hamelin (masters' student at the time of the study) and Dalia Kairy (associate professor, School of rehabilitation, Université de Montréal) for their assistance throughout the study. The 
authors would also like to thank the Centre for Interdisciplinary Research in Rehabilitation of Greater Montreal for their support in conducting the statistical analysis. 


\section{References}

1. Duncan PW, Horner RD, Reker DM, et al. Adherence to postacute rehabilitation guidelines is associated with functional recovery in stroke. Stroke. 2002;33(1):167-177.

2. Satterfield JM, Spring B, Brownson RC, et al. Toward a transdisciplinary model of evidence-based practice. Milbank Quartely. 2009;87(2):368-390.

3. Fakhry SM, Trask AL, Waller MA, Watts DD, IRTC Neurotrauma Task Force. Management of brain-injured patients by an evidence-based medicine protocol improves outcomes and decreases hospital charges. J Trauma. 2004;56(3):492-499; discussion 499-500.

4. Hunsley J, Mash EJ. Evidence-based assessment. Annu Rev Clin Psychol. 2007;3:29-51.

5. Unsworth CA. Evidence-based practice depends on the routine use of outcome measures. Br J Occup Ther. 2011;74(5):209.

6. Laver-Fawcett AJ. The importance of accurate assessment and outcome measurement. Principles of assessment and outcome measurement for occupational therapists and physiotherapists: theory, skills and application. Chichester: John Wiley; 2007:15-44.

7. Grol R, Grimshaw J. From best evidence to best practice: effective implementation of change in patients' care. Lancet. 2003;362(9391):1225-1230.

8. Strauss SE, Tetroe J, Graham ID. Knowledge translation: What it is and what it isn't. In: Strauss SE, Tetroe J, Graham ID, eds. Knowledge translation in health care: moving from evidence to practice. Chichester: UK: Jonh Wiley \& Sons; 2013:1-13.

9. Valdes K, MacDermid J, Algar L, et al. Hand therapist use of patient report outcome (PRO) in practice: a survey study. J Hand Ther. 2014;27(4):299-307; quiz 308. 
10. Korner-Bitensky N, Barrett-Bernstein S, Bibas G, Poulin V. National survey of Canadian occupational therapists' assessment and treatment of cognitive impairment post-stroke. Aust Occup Ther J. 2011;58(4):241-250.

11. Vogel AP, Maruff P, Morgan AT. Evaluation of communication assessment practices during the acute stages post stroke. J Eval Clin Pract. 2010;16(6):1183-1188.

12. Bowman J. Challenges to measuring outcomes in occupational therapy: a qualitative focus group study. Br J Occup Ther. 2006;69(10):464-472.

13. Stapleton T, McBrearty C. Use of standardised assessments and outcome measures among a sample of irish occcupational therapists working with adults with physical disabilities. Br J Occup Ther. 2009;72(2):55-64.

14. Jette DU, Halbert J, Iverson C, Miceli E, Shah P. Use of standardized outcome measures in physical therapist practice: perceptions and applications. Phys Ther. 2009;89(2):125135.

15. Jensen-Doss A, Hawley KM. Understanding barriers to evidence-based assessment: clinician attitudes toward standardized assessment tools. J Clin Child Adolesc Psychol. 2010;39(6):885-896.

16. Duncan EA, Murray J. The barriers and facilitators to routine outcome measurement by allied health professionals in practice: a systematic review. BMC Health Serv Res. 2012;12:96.

17. Graham ID, Logan J, Harrison MB, et al. Lost in knowledge translation: time for a map? J Contin Educ Health Prof. 2006;26(1):13-24. 
18. Légaré F, Zhang P. Barriers and facilitators. In: Strauss SE, Tetroe J, Graham ID, eds. Knowledge translation in health care: moving from evidence to practice. Chichester: UK: Jonh Wiley \& Sons; 2013:121-136.

19. Chaudoir SR, Dugan AG, Barr CH. Measuring factors affecting implementation of health innovations: a systematic review of structural, organizational, provider, patient, and innovation level measures. Implement Sci. 2013;8:22.

20. Dutil E, Forget A, Vanier M, Gaudreault C. Development of the ADL Profile: an evaluation for adults with severe head injury. Occup Ther Health Care. 1990;7:7-22.

21. Dutil E, Bottari C, Auger C. Test-retest reliability of a measure of independence in everyday activities: the ADL Profile. Occup Ther Int. 2017;2017, Article ID 3014579:17.

22. Damschroder LJ, Aron DC, Keith RE, Kirsh SR, Alexander JA, Lowery JC. Fostering implementation of health services research findings into practice: a consolidated framework for advancing implementation science. Implementation Sci. 2009;4:50.

23. Nilsen P. Making sense of implementation theories, models and frameworks. Implement Sci. $2015 ; 10: 53$.

24. Légaré F, O'Connor AM, Graham ID, et al. Primary health care professionals' views on barriers and facilitators to the implementation of the Ottawa Decision Support Framework in practice. Patient Educ Couns. 2006;63(3):380-390.

25. Huijg JM, Gebhardt WA, Dusseldorp E, et al. Measuring determinants of implementation behavior: psychometric properties of a questionnaire based on the theoretical domains framework. Implement Sci. 2014;9:33. 
26. Atkins L, Francis J, Islam R, et al. A guide to using the Theoretical Domains Framework of behaviour change to investigate implementation problems. Implement Sci. 2017;12(1):77.

27. McCluskey A, Vratsistas-Curto A, Schurr K. Barriers and enablers to implementing multiple stroke guideline recommendations: a qualitative study. BMC Health Serv Res. $2013 ; 13: 323$.

28. Cane J, O'Connor D, Michie S. Validation of the theoretical domains framework for use in behaviour change and implementation research. Implement Sci. 2012;7:37.

29. Cochrane LJ, Olson CA, Murray S, Dupuis M, Tooman T, Hayes S. Gaps between knowing and doing: understanding and assessing the barriers to optimal health care. $J$ Contin Educ Health Prof. 2007;27(2):94-102.

30. Michie S, Johnston M, Abraham C, et al. Making psychological theory useful for implementing evidence based practice: a consensus approach. Qual Saf Health Care. 2005;14(1):26-33.

31. Dutil E, Bottari C, Vanier M, Gaudreault C. ADL Profile : Description of the instrument (Version 4). Montreal: Québec: Emersion; 2005.

32. Rousseau J, Dutil E, Lambert J. Fidélité inter-examinateurs du "Profil des AVQ Mise en situation" chez la personne traumatisée cranio-cérébrale. Étude de la cote globale. Can J Occup Ther. 1994;61(3):149-158.

33. Rousseau J, Dutil E, Lambert J. Fidélité inter-examinateurs du "Profil des AVQ Mise en situation" chez la personne traumatisée cranio-cérébrale. Étude de la cote des opérations. Can J Occup Ther. 1994;61(3):159-167. 
34. Dutil E, Forget A, Rousseau J, Lambert J, Labelle J, Auger C. Activités de la vie quotidienne: Validation d'une approche évaluative. Proceedings of the Combined annual conference and exposition of the American Occupational Therapy Association and the Canadian Association of Occupational Therapists. Boston1994.

35. Tavakol M, Dennick R. Making sense of Cronbach's alpha. Int J Med Educ. 2011;2:5355.

36. Scott SD, Albrecht L, O'Leary K, et al. Systematic review of knowledge translation strategies in the allied health professions. Implement Sci. 2012;7:70.

37. Baker R, Camosso-Stefinovic J, Gillies C, et al. Tailored interventions to overcome identified barriers to change: effects on professional practice and health care outcomes. Cochrane Database Syst Rev. 2010;17(3):CD005470. 
Table 1 - MUST questionnaire subscales with associated constructs, construct definition and statements.

\begin{tabular}{|c|c|c|c|}
\hline Subscales & Constructs & Definition & Questionnaire statements \\
\hline \multirow{17}{*}{$\begin{array}{l}\text { Clinicians' } \\
\text { characteristics }\end{array}$} & Knowledge & Acknowledging the & 1. I know the objective of the tool \\
\hline & & existence of the tool, being & 2. I am familiar with the content of the tool \\
\hline & & familiar with its content and & 3. I am familiar with the theoretical constructs underlying the tool \\
\hline & & thinking of using the tool & 4. I know why it would be appropriate to use the tool in my clinical practice \\
\hline & & & o. 1 think or using the toor eacn time tha \\
\hline & Perceived self- & Clinicians' belief in their & 5. I feel familiar enough with the tool to use it \\
\hline & efficacy & own capability to use the & 25. In my clinical setting, I am able use the tool as indicated in the administration guide \\
\hline & & tool & 26. I have the ability to adequately administer the tool \\
\hline & & & 27. I am able to overcome difficulties encountered when using the tool \\
\hline & & & 28. Some aspects involved in administering the tool exceed my personal boundaries \\
\hline & & & 29. I am able to implement the tool in my practice \\
\hline & & & $\begin{array}{l}\text { *30. It is easy for me to provide verbal assistance consistent with the ADL Profile's } \\
\text { unstructured approach }\end{array}$ \\
\hline & & & 32. I am able to adequately use the tool's scoring system \\
\hline & Motivation & Motivation to use the tool & 33. It would be important to implement the tool in the clinical setting where I work \\
\hline & Emotion & Emotional response to the & 23. I am anxious when administrating the tool \\
\hline & & tool & 24. I feel cognitive overload when I administer the tool \\
\hline & & & 31. I am more confident in my recommendations when I use the tool \\
\hline \multirow{4}{*}{$\begin{array}{l}\text { Characteristics of } \\
\text { the Standardized } \\
\text { Assesment Tool }\end{array}$} & Professional & How compatible is the tool & 13. The tool is compatible with my professional scope of practice \\
\hline & role and identity & $\begin{array}{l}\text { with professional role and } \\
\text { standards of practice }\end{array}$ & 14. The tool is compatible with my professional code of ethics \\
\hline & $\begin{array}{l}\text { Professional } \\
\text { responsibility }\end{array}$ & $\begin{array}{l}\text { Risk of legal consequences } \\
\text { when using the tool }\end{array}$ & 55 The risk of lawsuits is greater if the tool is used \\
\hline & $\begin{array}{l}\text { Interpretation of } \\
\text { evidence }\end{array}$ & & $\begin{array}{l}\text { 7. The tool is supported by scientific evidence } \\
\text { 11. I doubt the scientific rigor of the tool }\end{array}$ \\
\hline
\end{tabular}


Anticipated

client outcome

Anticipated consequences for clients when using the tool

\section{Anticipated \\ outcome for the \\ evaluation \\ Anticipated impact that the}

process

Applicability to

clients'

Applicability of the tool to the clinical population

characteristics based on clients' characteristics

Applicability to Applicability of the tool to the clinical the client population based situation on the clinical situation

Agreement with Agreeing or not with the the use of the tool use of the tool; finding the tool too rigid or artificial to be used in clinical practice

Trialability

Being able to experiment with the tool before adopting it

Compatibility
18. The use of the tool will improve the health and well-being of clients

20. Information collected with the tool allows me to better understand my clients' needs compared to other assessments that I use

22. Results obtained with the tool provide information that ensures better client care than other assessments that I presently use

17. Information collected with the tool is more informative than the data collected with other tools

19. The tool collects information required to complete an assessment that is congruent with its intended goal

39. The evaluation methods used in the tool provide information that is essential to target clients' needs and interventions

8. The tool allows for more precise identification of the needs of my clientele

16. I think that the tool should be used systematically as an assessment tool with my clientele

9. The tool is applicable within my clinical setting

12. This standardized tool is too rigid to be used in my clinical practice

44. I disagree with a specific component of the tool, such as asking the client to carry out a certain task or to answer a certain question

36. I think it will be possible for me to experiment with the tool before adopting it

21. The use of the tool is compatible with my work setting's priorities 
The tool is consistent with the clinician's approach or with the organizational approach

Complexity

How easy or difficult it is to understand and use the tool

Communicable

Possibility to share as to reach mutual understanding of the results generated by the tool

Cost of

innovation

Benefits versus cost of using the tool in clinical practice

Clients'

preferences

Being able to reconcile client preferences with the use of the tool

Characteristics of Environmental the clinical resources

setting

Availability of human and material resources to

implement and use the too information with others so

37. The tool is compatible with my own evaluation approach

38. My work setting favours the use of tools that provide quantitative values (for example, a rating system or a total score)

$* 40$. It is important to be able to assess the client in his own real-world environment

*41. Evaluations carried out in real-world environments are compatible with the values of my work setting

*15. The non-structured evaluation approach advocated by the ADL Profile is difficult to put into practice

42. The implementation of the tool in my clinical practice will be difficult

*43. The limited information that can be given to clients regarding the evaluation process in order to respect the tool's non-structured evaluation approach limits my ability to obtain the client's free and informed consent

45. The training required for the proper use of the tool is an obstacle to the implementation of the tool in my clinical practice

46. It is easy to communicate/share the results of the tool with colleagues in my profession who know the tool

47. It is easy to communicate/share the results of the tool with colleagues in my profession who use other assessment tools

48. It is easy to communicate/share the results of the tool with colleagues from other professions

10. The benefits of using the tool outweigh the costs that may be incurred by its use

35. Some parts of the administration of the tool will be difficult to reconcile with my clients' interests setting
51. There are enough human and material resources to implement the tool in my work 
Organizational

climate

The extent to which the organization facilitates or hinders the implementation or use of the tool (e.g. team work, social pressure)

Time pressure Amount of time available to implement and use the tool
52. I have the support of my organization to learn or practice new methods

53. I have the support of my peers to implement the tool

54. My colleagues can help me with my workload while I familiarize myself with the too

49. I have the time to implement the tool in my practice

50. The tool takes too much time to administer

* Questions developed specifically for the ADL Profile that may not be relevant to other SATs 
Table 2-Cronbach's alphas for the three theoretical subscales of the MUST questionnaire

\begin{tabular}{lcc}
\hline Subscales & $\begin{array}{c}\text { Number of } \\
\text { statements }\end{array}$ & $\begin{array}{c}\text { Chronbach's } \\
\text { alphas }\end{array}$ \\
\hline Clinicians' characteristics & 18 & 0.762 \\
Characteristics of the standardized assessment tool & 31 & 0.832 \\
Characteristics of the clinical setting & 6 & 0.611 \\
\hline
\end{tabular}


Table 3 - Median and range for each statement of the pilot version of MUST questionnaire

\begin{tabular}{|c|c|c|}
\hline Statements & $\begin{array}{l}\text { Median } \\
\text { score }\end{array}$ & $\begin{array}{c}\text { Range } \\
(\text { min-max })\end{array}$ \\
\hline 1. I know the objective of the tool & 5 & $4-5$ \\
\hline 2. I am familiar with the content of the tool & 4 & $2-5$ \\
\hline 3. I am familiar with the theoretical constructs underlying the tool & 4 & $2-5$ \\
\hline 4. I know why it would be appropriate to use the tool in my clinical practice & 4 & $4-5$ \\
\hline 5. I feel familiar enough with the tool to use it & 4 & $2-5$ \\
\hline 6. I think of using the tool each time that it is required & 4 & $1-5$ \\
\hline 7. The tool is supported by scientific evidence & 4 & $3-5$ \\
\hline 8. The tool allows for more precise identification of the needs of my clientele & 4 & $3-5$ \\
\hline 9. The tool is applicable within my clinical setting & 4 & $2-5$ \\
\hline 10. The benefits of using the tool outweigh the costs that may be incurred by its use & 4 & $2-5$ \\
\hline 11. I doubt the scientific rigor of the tool & $4^{\dagger}$ & $2-5$ \\
\hline 12. This standardized tool is too rigid to be used in my clinical practice & $4^{\dagger}$ & $2-5$ \\
\hline 13. The tool is compatible with my professional scope of practice & 5 & $4-5$ \\
\hline 14. The tool is compatible with my professional code of ethics & 5 & $2-5$ \\
\hline 15. The non-structured evaluation approach advocated by the ADL Profile is difficult to put into practice & $3^{\dagger}$ & $1-5$ \\
\hline 16. I think that the tool should be used systematically as an assessment tool with my clientele & 2 & $1-5$ \\
\hline 17. Information collected with the tool is more informative than the data collected with other tools & 4 & 4-5 \\
\hline 18. The use of the tool will improve the health and well-being of clients & 4 & $2-5$ \\
\hline $\begin{array}{l}\text { 19. The tool collects information required to complete an assessment that is congruent with its intended } \\
\text { goal }\end{array}$ & 5 & $2-5$ \\
\hline $\begin{array}{l}\text { 20. Information collected with the tool allows me to better understand my clients' needs compared to } \\
\text { other assessments that I use }\end{array}$ & 4 & $3-5$ \\
\hline 21. The use of the tool is compatible with my work setting's priorities & 3 & $2-5$ \\
\hline $\begin{array}{l}\text { 22. Results obtained with the tool provide information that ensures better client care than other } \\
\text { assessments that I presently use }\end{array}$ & 4 & $2-5$ \\
\hline 23. I am anxious when administrating the tool & $3^{\dagger}$ & $2-5$ \\
\hline 24. I feel cognitive overload when I administer the tool & $3^{\dagger}$ & $1-5$ \\
\hline 25. In my clinical setting, I am able use the tool as indicated in the administration guide & 2 & $1-5$ \\
\hline 26. I have the ability to adequately administer the tool & 4 & $2-5$ \\
\hline
\end{tabular}


27. I am able to overcome difficulties encountered when using the tool

28. Some aspects involved in administering the tool exceed my personal boundaries

29. I am able to implement the tool in my practice

30. It is easy for me to provide verbal assistance consistent with the ADL Profile's unstructured approach

31. I am more confident in my recommendations when I use the tool

32. I am able to adequately use the tool's scoring system

33. It would be important to implement the tool in the clinical setting where I work

34. I am motivated to change my clinical habits and use the tool

35. Some parts of the administration of the tool will be difficult to reconcile with my clients' interests

36. I think it will be possible for me to experiment with the tool before adopting it

37. The tool is compatible with my own evaluation approach

38. My work setting favours the use of tools that provide quantitative values (for example, a rating system or a total score)

39. The evaluation methods used in the tool provide information that is essential to target clients' needs and interventions

40. It is important to be able to assess the client in his own real-world environment

41. Evaluations carried out in real-world environments is compatible with the values of my work setting

42. The implementation of the tool in my clinical practice will be difficult

43. The limited information that can be given to clients regarding the evaluation process in order to respect the tool's non-structured evaluation approach limits my ability to obtain the client's free and informed consent

44. I disagree with a specific component of the tool, such as asking the client to carry out a certain task or to answer a certain question

45. The training required for the proper use of the tool is an obstacle to the implementation of the tool in my clinical practice

46. It is easy to communicate/share the results of the tool with colleagues in my profession who know the tool

47. It is easy to communicate/share the results of the tool with colleagues in my profession who use other assessment tools

48. It is easy to communicate/share the results of the tool with colleagues from other professions

49. I have the time to implement the tool in my practice

50. The tool takes too much time to administer

51. There are enough human and material resources to implement the tool in my work setting 
52. I have the support of my organization to learn or practice new methods

53. I have the support of my peers to implement the tool

54. My colleagues can help me with my workload while I familiarize myself with the tool

55. The risk of lawsuits is greater if the tool is used

${ }^{\dagger}$ These statements were reverse scored because the statements are reverse worded 


\section{SUPPLEMENTAL DIGITAL CONTENT}

Final version of the

'Measure of potential barriers and facilitators to Using a

Standardized assessment Tool (MUST)'

Priscilla Lam Wai Shun, OT, MSc, PhD(c)

Carolina Bottari, OT, PhD, Associate Professor

Occupational Therapy Program, School of Rehabilitation, Université de Montréal

Centre for Interdisciplinary Research in Rehabilitation of Greater Montreal

Montreal, Quebec, Canada.

\section{Corresponding author:}

Dr. Carolina Bottari

Faculty of Medicine, School of Rehabilitation, Université de Montréal

C.P. 6128 Succursale Centre-Ville

Montreal (Québec)

Canada, $\mathrm{H} 3 \mathrm{C} 3 \mathrm{~J} 7$

Telephone number: 514-343-6111, ext. 44048

Email: carolina.bottari@umontreal.ca 


\section{Measure of potential barriers and facilitators to Using a \\ Standardized assessment Tool (MUST)}

Please score each statement using the following scale:

\begin{tabular}{ccccc}
\hline 1 & 2 & 3 & 4 & 5 \\
\hline $\begin{array}{l}\text { Strongly } \\
\text { disagree }\end{array}$ & Disagree & $\begin{array}{l}\text { Without } \\
\text { opinion }\end{array}$ & Agree & Strongly agree \\
\hline
\end{tabular}

1 I know the objective of the tool

$\begin{array}{lllll}1 & 2 & 3 & 4 & 5\end{array}$

2 I am familiar with the content of the tool

$\begin{array}{lllll}1 & 2 & 3 & 4 & 5\end{array}$

3 I am familiar with the theoretical constructs underlying the tool

$\begin{array}{lllll}1 & 2 & 3 & 4 & 5\end{array}$

4 I know why it would be appropriate to use the tool in my clinical practice

$\begin{array}{lllll}1 & 2 & 3 & 4 & 5\end{array}$

5 I feel familiar enough with the tool to use it

$\begin{array}{lllll}1 & 2 & 3 & 4 & 5\end{array}$

Within my client caseload, I am able to identify clients for whom the use of the tool would be relevant

$\begin{array}{lllll}1 & 2 & 3 & 4 & 5\end{array}$

$7 \quad$ The tool is supported by scientific evidence

$\begin{array}{lllll}1 & 2 & 3 & 4 & 5\end{array}$

The tool allows for more precise identification of the needs of my

8 clientele

$\begin{array}{lllll}1 & 2 & 3 & 4 & 5\end{array}$

*9 The interview with the client is applicable within my clinical setting

$\begin{array}{lllll}1 & 2 & 3 & 4 & 5\end{array}$

The interview with the significant other is applicable in my clinical

*10 setting

$\begin{array}{lllll}1 & 2 & 3 & 4 & 5\end{array}$

All tasks included in the performance based assessment are applicable

*11 in my clinical setting

$\begin{array}{lllll}1 & 2 & 3 & 4 & 5\end{array}$ 
The benefits of using the tool outweigh the costs that may be incurred
12 by its use

13 I doubt the scientific rigor of the tool

14 This standardized tool is too rigid to be used in my clinical practice

15 The tool is compatible with my professional scope of practice

16 The tool is compatible with my professional code of ethics

*17 The non-structured evaluation approach advocated by the ADL Profile is difficult to put into practice

18 I think that the tool should be used systematically to assess clients for whom the tool was developed for

Information collected with the tool is more informative than the data

19 collected with other tools

20 The use of the tool will improve the health and well-being of clients

The tool collects information required to complete an assessment that is

21 congruent with its intended goal

Information collected with the tool allows me to better understand my

22 clients' needs compared to other assessments that I use

23 The use of the tool is compatible with my work setting's priorities

The results obtained with the tool provide more complete information

24 The results obtained with the tool provide
than other assessments that I presently use

25 I am anxious when administrating the tool

26 I feel cognitive overload when I administer the tool $\begin{array}{lllll}1 & 2 & 3 & 4 & 5\end{array}$

$\begin{array}{lllll}1 & 2 & 3 & 4 & 5\end{array}$

$\begin{array}{lllll}1 & 2 & 3 & 4 & 5\end{array}$

$\begin{array}{lllll}1 & 2 & 3 & 4 & 5\end{array}$

$\begin{array}{lllll}1 & 2 & 3 & 4 & 5\end{array}$

$\begin{array}{lllll}1 & 2 & 3 & 4 & 5\end{array}$

$\begin{array}{lllll}1 & 2 & 3 & 4 & 5\end{array}$

$\begin{array}{lllll}1 & 2 & 3 & 4 & 5\end{array}$

$\begin{array}{lllll}1 & 2 & 3 & 4 & 5\end{array}$

$\begin{array}{lllll}1 & 2 & 3 & 4 & 5\end{array}$

$\begin{array}{lllll}1 & 2 & 3 & 4 & 5\end{array}$

$\begin{array}{lllll}1 & 2 & 3 & 4 & 5\end{array}$

$\begin{array}{lllll}1 & 2 & 3 & 4 & 5\end{array}$

$\begin{array}{lllll}1 & 2 & 3 & 4 & 5\end{array}$

125

$\begin{array}{lllll}1 & 2 & 3 & 4 & 5\end{array}$ 
*27 I feel cognitive overload when I analyze clients' performance using this tool.

$\begin{array}{lllll}1 & 2 & 3 & 4 & 5\end{array}$

28 In my clinical setting, I am able to use the tool as indicated in the administration guide

$\begin{array}{lllll}1 & 2 & 3 & 4 & 5\end{array}$

29 I have the ability to adequately administer the tool

$\begin{array}{lllll}1 & 2 & 3 & 4 & 5\end{array}$

I am confident of being able to overcome difficulties encountered when using the tool

$\begin{array}{lllll}1 & 2 & 3 & 4 & 5\end{array}$

I feel uneasy when administering some parts of the tool because I need to perform certain actions that exceed my personal boundaries

$\begin{array}{lllll}1 & 2 & 3 & 4 & 5\end{array}$

32 I am able to implement the tool in my practice

$\begin{array}{lllll}1 & 2 & 3 & 4 & 5\end{array}$

I am confident of being able to provide verbal assistance as advocated

*33 by the ADL Profile's unstructured approach

$\begin{array}{lllll}1 & 2 & 3 & 4 & 5\end{array}$

34 I feel that I will be more confident in my recommendations when I use the tool

$\begin{array}{lllll}1 & 2 & 3 & 4 & 5\end{array}$

35 I am able to adequately use the tool's scoring system

$\begin{array}{lllll}1 & 2 & 3 & 4 & 5\end{array}$

36 It would be important to implement the tool in the clinical setting where I work

$\begin{array}{lllll}1 & 2 & 3 & 4 & 5\end{array}$

37 I am motivated to change my clinical habits and use the tool

$\begin{array}{lllll}1 & 2 & 3 & 4 & 5\end{array}$

Some parts of the administration of the tool will be difficult to reconcile with my clients' interests

$\begin{array}{lllll}1 & 2 & 3 & 4 & 5\end{array}$

I think it will be possible for me to experiment with the tool before adopting it

$\begin{array}{lllll}1 & 2 & 3 & 4 & 5\end{array}$

40 The tool is compatible with my own evaluation approach

$\begin{array}{lllll}1 & 2 & 3 & 4 & 5\end{array}$

My work setting favours the use of tools that provide quantitative values (for example, a rating system or a total score)

$\begin{array}{lllll}1 & 2 & 3 & 4 & 5\end{array}$ 
The evaluation methods used in the tool provide information that is essential to target clients' needs and interventions

$\begin{array}{lllll}1 & 2 & 3 & 4 & 5\end{array}$

It is important to be able to assess the client in his own real-world environment

$\begin{array}{lllll}1 & 2 & 3 & 4 & 5\end{array}$

The use of a non-structured approach is essential to obtain

*44 comprehensive information on the level of independence of a client with cognitive deficits.

*45 Evaluations carried out in real-world environments are compatible with the values of my work setting

46 The implementation of the tool in my clinical practice will be difficult $\quad \begin{array}{lllll}1 & 2 & 3 & 4 & 5\end{array}$

The limited information that can be provided to clients regarding the

*47 evaluation process in order to respect the tool's non-structured evaluation approach limits my ability to obtain the client's free and informed consent

48 I think specific components of the tool, such as asking the client to carry out a certain task or to answer a certain question, will be problematic in my clinical practice

The training required for the proper use of the tool is an obstacle to the implementation of the tool in my clinical practice

The way the tool is designed facilitates communication/sharing of results with colleagues in my profession who know the tool

The way the tool is designed facilitates communication/sharing of results with colleagues in my profession who use other assessment tools

The way the tool is designed facilitates communication/sharing of information with colleagues from other professions

I have the time to familiarize myself with the tool and to try it out with clients

The tool takes too much time to administer in the context of my clinical practice 
56 I have the support of my organization to learn or practice new methods $\quad \begin{array}{lllll}5 & 2 & 3 & 4 & 5\end{array}$

57 I have the support that I need from my peers to implement the tool in $\begin{array}{rrrrr}1 & 2 & 3 & 4 & 5 \\ \text { my clinical practice }\end{array}$

58 The risk of lawsuits is greater if the tool is used $\quad 1 \quad 2 \quad 3 \quad 4 \quad 5$

* Questions developed specifically for the ADL Profile may not be relevant to other standardized assessment tools 